\title{
Comparing Conventional and New Policy Approaches for Carnivore Conservation \\ Theoretical Results and Application to Tiger Conservation
}

\author{
Journal Article \\ Author(s): \\ Zabel, Astrid; Pittel, Karen; Bostedt, Goran; Engel, Stefanie \\ Publication date: \\ 2011-02 \\ Permanent link: \\ https://doi.org/10.3929/ethz-b-000032610
}

Rights / license:

In Copyright - Non-Commercial Use Permitted

Originally published in:

Environmental and Resource Economics 48(2), https://doi.org/10.1007/s10640-010-9411-4 


\title{
Comparing Conventional and New Policy Approaches for Carnivore Conservation: Theoretical Results and Application to Tiger Conservation
}

\author{
Astrid Zabel • Karen Pittel • Göran Bostedt • \\ Stefanie Engel
}

Accepted: 13 May 2010 / Published online: 22 September 2010

(C) Springer Science+Business Media B.V. 2010

\begin{abstract}
New policy approaches to facilitate the co-existence of wildlife and livestock are needed for situations where predation incidents greatly impact households' income and retaliatory killing threatens endangered carnivore species' survival. In this paper, models are developed to assess how two alternative policy approaches impact a herder's decisions on carnivore hunting and livestock protection. We find that while the well-established expost compensation policy induces suboptimal livestock protection it can generate sufficient incentives for the herder to refrain from hunting so that the carnivore population reaches its socially optimal level. Performance payments are proposed as alternative policy. They are found not to distort livestock protection incentives and can also help achieve a socially optimal carnivore population level. Which of the two scheme types gives rise to less cost is ambiguous. An empirical analysis of the model with data from tiger-livestock conflicts in India is presented.
\end{abstract}

Keywords Biodiversity conservation - India - Payments for environmental services . Performance payments · Conservation incentives · Wildlife-livestock conflicts

JEL Classification Q20

\footnotetext{
A. Zabel $(\varangle) \cdot$ S. Engel

Institute for Environmental Decisions (IED), Environmental Policy and Economics, Swiss Federal Institute of Technology, ETH, Universitaetsstr. 16, 8092 Zurich, Switzerland e-mail: astrid.zabel@env.ethz.ch

K. Pittel

Ifo Institute for Economic Research and the University of Munich, Munich, Germany

G. Bostedt

Department of Forest Economics and Centre for Environmental and Resource Economics, CERE, Swedish University of Agricultural Sciences, SLU,

90183 Umeå, Sweden

e-mail: goran.bostedt@sekon.slu.se
} 


\section{Introduction}

Today, a fourth of all carnivores assessed by the IUCN are critically endangered, endangered, or vulnerable (Hilton-Taylor et al. 2009). Carnivores are top predators and have an important regulatory function that helps stabilize ecosystems. Many are also so-called umbrella species because their demand for large territories simultaneously enables the conservation of other species that share the same habitat. Three-fourths of the felid group, to which tigers belong, are reported to be in conflict with humans (Inskip and Zimmermann 2009). Poaching in retaliation of predation on livestock is an important factor constraining carnivore survival in the wild. Other major constraining factors are poaching for trophies and habitat loss (Hazzah et al. 2009; Gusset et al. 2009; Karanth and Chellam 2009). Conflicts between humans and wildlife are estimated to be the most acute in the tropics due to the rapidly increasing human demand for land and scarce resources (Madhusudan 2003).

This paper focuses on assessing the effects of two conservation policy approaches, ex-post compensation and performance payments, on livestock herders' incentives to hunt carnivores and protect livestock. Implementing conservation policies is particularly important in regions where loss of livestock to carnivore attacks is devastating for poor farmers. Without external payments, they may have very little incentives to support carnivore conservation initiatives. In rural societies livestock is often not only source of food and income, but also a form of saving and can be a means of transportation (Thirgood et al. 2005; Woodroffe et al. 2005; Mishra 1997).

In terms of annual income, case studies from India and Africa reveal that households situated close to wildlife reserves, on average, lose between 12 and $19 \%$ of their annual income due to predation by carnivores (Madhusudan 2003; Holmern et al. 2006; Butler 2000).

During the last decades, various policy approaches have been developed and implemented to alleviate wildlife-livestock conflicts, e.g. fences and fines approaches (Casey et al. 2006), ex-post compensation, and benefit sharing strategies, sometimes referred to as Communitybased Wildlife Management, CWM (see Songorwa 1999, for a critical evaluation). Evidence is scarce that these approaches have been successful in creating true pro-conservation incentives among livestock herders. New policy approaches to facilitate the co-existence of wildlife and livestock are increasingly being sought-after as human sprawl increases and carnivore populations decrease.

In the literature several models have been developed to investigate these different policy approaches. Bulte and Rondeau (2007) criticize the general presumption that paying compensation to offset damage caused by wildlife supports conservation. They find that compensation payments have ambiguous effects on wildlife stocks and local welfare because they may reduce hunting efforts but simultaneously provide incentives to convert natural habitat into agricultural land which is detrimental for wildlife.

Skonhoft's (1998) model focuses on a cost and benefit sharing policy approach. The conclusion is that providing locals with benefits from hunting and tourism is a promising approach to reduce incentives for illegal poaching.

The effects of benefit sharing programs on communities' incentives to conserve wildlife are also addressed in a model by Fischer et al. (2005). They find that wildlife conservation programs, such as CAMPFIRE, that focus on sharing resource profits do not necessarily result in net benefits for the communities. Whether profit sharing succeeds in providing conservation incentives to communities is found to depend on (a) the type of resource profits that are shared, (b) to what extent the shared profits offset the agricultural losses, and (c) the feedback of community-external actors in terms of changes in their resource management practices. Very similar to Skonhoft (1998) they point out that to strengthen locals' incentives 
for conservation, there must be a straight-forward and comprehensible link between locals' actions, changes in the park's wildlife stock and profits shared with the community. If locals receive payments that are disjuncted from their actions and changes in the park's wildlife stock, this monetary transfer will not affect their conservation incentives.

Conservation performance payments, which are a type of payments for environmental services, are a relatively new policy approach and have not been analyzed in previous models of wildlife conservation. Performance payments are monetary or in-kind payments made by a paying agency to individuals or groups and are conditional on specific conservation outcomes (Albers and Ferraro 2006; Engel et al. 2008). In our context, the conservation outcome is the size of the wildlife stock (or a function of stock such as offspring). Performance payments are suggested to be more direct and more cost-effective than alternative approaches (Ferraro and Simpson 2002; Wätzold and Drechsler 2005; Casey and Boody 2007). To our knowledge, in the carnivore conservation context the only existing large-scale performance payment scheme is currently implemented in Sweden (Zabel and Holm-Müller 2008). ${ }^{1}$

The purpose of this paper is to add to the above-mentioned literature on wildlife conservation policies by analyzing the effects of conservation performance payments in comparison to the more conventional ex-post compensation approach. Bulte and Rondeau (2007) also investigate ex-post compensation but they do not discuss performance payments. An important difference of our model is that protection against wildlife damage is not necessarily lethal for wildlife. We rather allow for both a lethal and a non-lethal strategy. Furthermore, we focus on interior solutions whereas Bulte and Rondeau (2007) focus mainly on corner solutions.

The paper is structured as follows: Sect. 2 introduces the theoretical model developed to compare the alternative policy schemes. In Sect. 3, the focus is on the two policy approaches (a) ex-post compensation and (b) performance payments. Section 4 compares program costs for the two approaches and in Sect. 5 an empirical simulation of the model with data from tiger-livestock conflicts in India is presented. Section 6 discusses and summarizes the results.

\section{The Model}

The analysis starts by taking the view of a social planner whose goal is to maximize society's welfare. The social planner takes into account the costs and benefits that accrue to a livestock herder as well as society's existence value for the carnivore population. In a next step, we determine the outcome for a homo-economicus livestock herder who optimizes his income in the absence of policy measures.

The theoretical model presented here draws on the models developed in Damania et al. (2003), and Bostedt $(2001 ; 2005)$, the latter in turn have connections to other models of agricultural households (e.g. Singh et al. 1986), as well as models of self-employed forest owners (e.g. Johansson and Löfgren 1985, chapter 7). The most important difference compared with these previous models is that this model focuses on the effects of large carnivores on pastoralist livestock herders, and on the incentives for livestock protection and poaching caused by different compensation systems. Furthermore, for simplicity, we focus on a static model.

We assume that the livestock herder does not internalize society's existence value for carnivores and it is further assumed that the herder personally assigns no existence value to

1 See Wunder et al. (2008) for a recent review of payment for environmental services schemes in other contexts. 
carnivores. Thus by intuition, the carnivore population in the livestock herder's optimal solution must be smaller than the carnivore population in the social planner's solution. The goal of the analysis is to determine how alternative policy mechanisms can influence the livestock herder's decision making process and eventually alter his optimal carnivore population. In Sect. 3, the first order conditions for effort in livestock protection and hunting of carnivores derived from the social planner scenario are used as a benchmark to compare and evaluate the two alternative policy mechanisms (a) ex-post compensation and (b) performance payments.

\subsection{Social Planner}

The social planner maximizes the income of the representative livestock herder plus the existence value of the carnivore population

$$
\psi^{S P}=\max _{l, a, o}[p *(h-k(W(l), a))+r o+Z(W(l))]
$$

subject to the herder's time constraint

$$
L=o+l+a
$$

with $o, l, a, L, h, p, r \geq 0$

where the superscript $S P$ stands for social planner. $L$ is the labor constraint, and the herder can invest his working time in off-farm work, $o$, hunting carnivores, $l$, or livestock protection, $a$. Leisure time is assumed to be fixed. Livestock's exogenous unit price is $p$. The number of livestock available for sale is the difference between the livestock herd, $h$, and predation by carnivores, $k(W(l), a)$. Predation is a function of carnivore stock, $W(l)$ (with $W_{l}<0$ and $W_{l l}>0$, (subscripts indicate the argument of a derivative), and the herder's protection effort, $a$. Predation is assumed to be increasing in carnivores, $k_{W}>0$. In principle, the second derivative may be positive, zero, or negative, as long as the overall quasiconcavity of the objective function in (1) is satisfied, which we assume to be the case. Predation decreases in the time the herder spends protecting livestock, $k_{a}<0 \quad k_{a a} \geq 0$. The term $r o$ captures the herder's off-farm income. It is the product of the exogenously given off-farm wage rate, $r$, and time spent working off-farm, $o$.

Finally, the social planner also takes society's existence value of the carnivore population, $Z(W)$, into account. It is assumed that marginal existence values are positive $\left(Z_{W}>\right.$ $\left.0, Z_{W W}<0\right)$.

The labor constraint (2) can be substituted into (1) so that the maximization problem simplifies to

$$
\psi^{S P}=\max _{l, a}[p *(h-k(W(l), a))+r(L-l-a)+Z(W(l))]
$$

The first order condition with respect to protection effort (effort is used as synonym to labor) is

$$
\psi_{a}^{S P}=-p k_{a}-r=0
$$

The first order condition with respect to hunting effort is

$$
\psi_{l}^{S P}=-p k_{W} W_{l}-r+Z_{W} W_{l}=0
$$

The first order condition for protection effort (4) states that the monetary value of livestock saved per marginal unit of protection effort is equal to the opportunity cost of effort, the off-farm wage rate, $r$. 
Equation (5) states that the benefit of a marginal unit of hunting effort, $-p k_{W} W_{l}>0$, which is the monetary value of livestock not killed due to hunted predators, equals the loss of existence value of the carnivores killed per marginal unit of hunting effort, $-Z_{W} W_{l} \geq 0$, plus the opportunity cost of time spent hunting, i.e. the off-farm wage rate $r$.

If the benefit of hunting is smaller than cost at all levels of $l$, so $-p k_{W} W_{l}<r-Z_{W} W_{l}, \forall l$, a corner solution will arise in which zero hunting is optimal. In the following we will focus on interior solutions.

\subsection{Livestock Herder}

As discussed earlier, by intuition, the livestock herder who does not internalize carnivores' existence value will favor a smaller carnivore population than the social planner.

To formalize this intuition, the livestock herder's optimization problem is set up. The only difference to the social planner scenario developed above is that it does not include the term for the existence value, $Z(W(l))$.

The livestock herder, indicated by the superscript $L H$, maximizes his income subject to his labor constraint which is already substituted into (6):

$$
\psi^{L H}=\max _{l, a}[p *(h-k(W(l), a))+r(L-l-a)]
$$

The resulting first order conditions for protection and hunting effort are

$$
\begin{aligned}
& \psi_{a}^{L H}=-p k_{a}-r=0 \\
& \psi_{l}^{L H}=-p k_{W} W_{l}-r=0
\end{aligned}
$$

Equations (5) and (8) can be compared to investigate differences in optimal hunting effort and the resulting carnivore population in the social planner and the livestock herder models. Since the livestock herder does not ascribe an existence value to carnivores, the cost of hunting in terms of foregone existence value, $Z_{W} W_{l}$, does not arise in his optimality condition. In absence of these costs, the marginal return to hunting is higher in the livestock herder model than in the social planner model. In consequence, the optimal amount of hunting effort is higher in the livestock herder model than in the social planner model. Since carnivore stock is a function of hunting effort, this confirms the intuition that the herder's optimal carnivore population is smaller than the social planner's.

A comparison of the optimality conditions for protection effort in the social planner model (4) and the livestock herder model (7) reveals that the decision rule for the optimal amount of protection effort is the same. However, the optimal amount of protection effort in the livestock herder model may change with changes in the optimal amount of hunting effort. Whether this is the case depends on the functional relationship of carnivore stock and livestock protection effort in the predation function. Two general relationships are worth considering: (a) separable and (b) non-separable. In the separable case $k_{a W}=k_{W a}=0$ and in the non-separable case $k_{a W}=k_{W a}<0$. For a separable functional relationship, the carnivore population size does not affect marginal returns to livestock protection so that the livestock herder's protection effort is equal to the socially optimal amount. For a non-separable relationship the herder's protection effort level is lower than the optimal amount because the suboptimal carnivore population size resulting from (8) decreases returns to labor in livestock protection in (7). 


\section{Policy Analysis}

The optimal amount of hunting effort and the resulting carnivore population in the social planner model can now be defined as the benchmark that is supposed to be attained by means of alternative policy mechanisms. Two policies, (a) ex-post compensation and (b) performance payments, will be analyzed for their potential to shift the livestock herder's optimal carnivore population closer to the that defined in the social planner model.

\subsection{Ex-Post Compensation}

Ex-post compensation means that livestock herders receive a certain amount of money for livestock lost in carnivore attacks. This is a rather common policy in Europe and the US but also in developing countries such as India or Kenya (Saberval et al. 1994; Mishra 1997; Fourli 1999; Madhusudan 2003; Western and Waithaka 2005). Several problems inherent to ex-post compensation schemes have been identified. In particular these are (a) moral hazard, (b) long time lags between the predation incident and the actual payment, (c) high transaction costs, and (iv) problems of trust and transparency (Nyhus et al. 2005; Zabel and Holm-Müller 2008).

Ex-post compensation is included into the livestock herder model as the product of the compensation payment, $q$, and the number of livestock that are killed by carnivores, $k(W(l), a)$. This term is added to the herder's income statement in Eq. (6) to obtain the new optimization problem. The superscript LHex - post indicates the livestock herder problem under an ex-post compensation scheme.

$$
\psi^{L H e x-p o s t}=\max _{l, a}[p *(h-k(W(l), a))+q k(W(l), a)+r(L-l-a)]
$$

The first order conditions for hunting and protection effort under the ex-post compensation scheme are as follows.

$$
\begin{aligned}
& \psi_{a}^{\text {LHex-post }}=(q-p) k_{a}-r=0 \\
& \psi_{l}^{\text {LHex }- \text { post }}=(q-p) k_{W} W_{l}-r=0
\end{aligned}
$$

The first order condition for livestock protection effort in (9) reveals that the compensation payment reduces the marginal return to effort which implies that (if $q>0$ ) the herder will spend less than the socially optimal amount of time protecting his livestock. In their model, Bulte and Rondeau (2007) term this effect of issuing a compensation payment moral hazard. There are similarities to classical models of moral hazard (e.g. Spence and Zeckhauser 1971) but in our model, as well as in Bulte and Rondeau (2007), hidden action is not explicitly modeled. We thus simply regard this effect as a reduced incentive to protect livestock.

Whether this effect will also impact the decision on hunting effort in (10) again depends on the functional relationship of carnivore stock and livestock protection effort in the predation function. For a separable relationship, marginal predation is independent of protection effort, $k_{W a}=0$. The hunting effort decision is thus not impacted by the reduced livestock protection effort. The compensation payment simply reduces marginal returns to labor in hunting effort.

Above, we have developed the social planner's optimality condition for hunting effort, (5) which, compared to the herder's first order condition in the absence of policies, (8), contained 
the additional term $Z_{W} W_{l}$. The optimal compensation payment (11) is obtained by equating the LHS of (5) and (10)

$$
q^{*}=\frac{Z_{W}}{k_{W}}
$$

The compensation payment equals carnivores' marginal existence value divided by marginal predation. It will provide incentives for the herder to invest the socially optimal amount of hunting effort. Since carnivore stock is a direct function of hunting effort, specifying the compensation payment in this way will also result in the optimal carnivore stock.

Time lags between the actual predation incident and the payment of the compensation have often been mentioned as obstacle to the functioning of this type of scheme. A time lag would reduce the payment by a certain factor due to the depreciation. With such a suboptimal payment the herder will spend more than the socially optimal time hunting. In the following we will assume timely payments.

However, the case is different for a non-separable relationship of carnivores and protection effort in the predation function, where marginal predation is assumed to decrease in livestock protection effort, $k_{W a}<0$, or equivalently, a decrease in protection effort due to the compensation payments will result in an increase in marginal predation in Eq. (10). This will increase the marginal return to hunting effort because a larger number of livestock is saved from predation per marginal unit of effort the herder spends hunting.

The correct compensation payment is found by equating the LHS of the social planner's first order condition for effort in hunting (5) to the LHS of the herder's equivalent first order condition (10). Note that for the non-separable case, marginal predation is higher in the herder's first order condition than the social planner's, $k_{W}^{L H}>k_{W}^{S P}$. Thus they do not cancel out when equating the LHS of (5) and LHS of (10). The resulting condition for the compensation payment is as follows

$$
q^{*}=\frac{Z_{W} W_{l}+p W_{l}\left(k_{W}^{L H}-k_{W}^{S P}\right)}{k_{W}^{L H} W_{l}}
$$

This compensation payment internalizes carnivores' existence value and the consequences of suboptimal livestock protection into the herder's decision on hunting effort. The first term on the RHS is the marginal existence value that is lost per livestock saved through hunting of carnivores under the herder's sub-optimal protection conditions. The second term is the value of the livestock that can additionally be saved per marginal unit of hunting (because suboptimal protection increases marginal predation) divided by the marginal number of livestock saved through hunting under low protection conditions.

To conclude, for both separable and non-separable predation functions, optimal compensation payment plans can been found through which the herder can be incentivized to sustain the socially optimal carnivore population. However, the calculations of the optimal compensation payment in the non-separable case (12) is complex and requires estimation of existence value and predation functions, as well as hunting technologies. Moreover, ex-post compensation leads to a problem of suboptimal protection incentives.

\subsection{Performance Payments}

In the performance payment approach, the payments are directly linked to the size of the wildlife stock (or a function of stock, such as offspring). The Swedish case, which to our knowledge is the only large-scale performance payment scheme for carnivore conservation, illustrates the approach. There, the government has defined explicit goals for the size of the 
wolverine and lynx populations that it would like to host in the country (Swedish Government Bill 2000). Wolverines (Gulo gulo), which are listed as vulnerable on the IUCN red list of endangered species (Mustelid Specialist Group 1996) and lynx (Lynx lynx) are two predators that feed on reindeer and cause great economic damage to the indigenous reindeer herding Sami people (Persson 2005; Swenson and Andren 2005; Danell et al. 2006). The semidomesticated reindeer are kept in a nomadic system and are moved between lowlands and mountains depending on season. Until 1996, an ex-post compensation scheme was installed under which the herders could claim compensation for reindeer that were verified to have been killed by carnivores. In 1996, the ex-post compensation scheme was abolished and replaced by a performance payment scheme. Today, the reindeer herders are remunerated based on the number of carnivore offspring that are certified on their reindeers' grazing grounds. This has the advantage of providing very straightforward pro-conservation incentives (Zabel and Holm-Müller 2008). The main activities that the reindeer herders can engage in to promote carnivore conservation are to refrain from (illegal) poaching and to let reindeer roam free as potential food for carnivores. Illegal poaching of carnivores is a serious issue in Sweden (Swedish National Council for Crime Prevention 2007). In a long-term study 60\% of adult mortality among wolverines and $46 \%$ among lynx was ascribed to illegal poaching (Persson 2007; Andrén et al. 2006). However, data from the annual carnivore inventories suggests that especially the endangered wolverine population is facing an upward trend in recent years. This population increase must be interpreted and appreciated with care since next to anthropogenic influences natural environmental factors and improved data collection methods may also play a role.

The performance payments can be incorporated into the livestock herder's maximization problem (indicated by the superscript LHperformance) as a function of the carnivore population, $V(W(l))$.

$$
\psi^{\text {LHperformance }}=\max _{l, a}[p *(h-k(W(l), a))+r(L-l-a)+V(W(l))]
$$

The first order conditions for livestock protection and carnivore hunting are

$$
\begin{aligned}
& \psi_{a}^{\text {LHperformance }}=-p k_{a}-r=0 \\
& \psi_{l}^{\text {LHperformance }}=-p k_{W} W_{l}-r+V_{W} W_{l}=0
\end{aligned}
$$

A comparison of (14) with (4) reveals the interesting result that performance payments do not distort a herder's incentives to optimally protect his livestock. He will allocate the socially optimal level of effort to livestock protection irrespective of the amount of the performance payment. This is clearly an advantage over ex-post compensation which was found to induce suboptimal livestock protection.

A condition for the optimal performance payment can be derived by equating the herder's first order condition for hunting effort (15) to the social planner's equivalent first order condition in (5). This reveals that if the marginal performance payment equals carnivores' marginal existence value at the optimal level of hunting effort

$$
V_{W}=Z_{W}
$$

the performance payment will incentivize the herder to achieve the socially optimal carnivore population. This requires only one crucial piece of information; knowledge on the marginal existence value for the carnivore population, $Z_{W}$. 


\section{Comparison of Program Cost}

An interesting question is which program will cause higher costs once the social optimum is achieved. This is of interest because program budgets are frequently limited, and raising program funds is likely to cause transaction costs (Wünscher et al. 2008). For an interior solution of the model, program costs (denoted as $C$ ) at the social optimum under the ex-post compensation scheme are given by

$$
C^{e x-p o s t}=q^{*} k\left(W\left(l^{S P}\right), a^{L H}\right)
$$

where for the separable predation function $q^{*}=\left.\frac{Z_{W}}{k_{W}}\right|_{W=W^{S P}}$ and for the non-separable predation function $q^{*}=\left.\frac{Z_{W}+p\left(k_{W}^{L H}-k_{W}^{S P}\right)}{k_{W}^{L H}}\right|_{W=W S P}$

For tractability we assume here that the performance payment takes the form of a constant per unit payment. This is the case in the Swedish scheme and also, more generally, for most payment for environmental services schemes implemented to date (Wunder et al. 2008). The costs for a performance payment scheme at the social planner's optimum can be written as

$$
C^{\text {performance }}=V\left(W\left(l^{S P}\right)\right)=Z_{W} * W\left(l^{S P}\right) \text {, where }\left.Z_{W}\right|_{W=W} S P .
$$

Comparing the cost of ex-post compensation in case of a separable predation function such as $k\left(W\left(l^{S P}\right), a^{L H}\right)=k^{i}\left(W\left(l^{S P}\right)\right)-k^{i i}\left(a^{L H}\right)$ with the cost of a performance payment scheme we find that $\frac{k^{i}\left(W\left(l^{S P}\right)\right)}{W\left(l^{S P}\right)}-k_{W}^{i}<\frac{k^{i i}\left(a^{L H}\right)}{W\left(l^{S P}\right)}$ so that $C^{\text {ex-post }}<C^{\text {performance }}$ for linear and convex forms of $k^{i}(W(l))$ (that do not contain constant summands). For concave forms of $k^{i}(W(l))$, which scheme is less expensive is ambiguous.

By intuition, ex-post compensation for separable predation functions (at least for linear and convex forms) is less expensive because the optimal payment is computed irrespective of the herder's protection effort, thus indirectly assuming predation levels that occur only in complete lack of protection effort. However, compensation only needs to be paid for the actual losses which are lower than assumed because, unless livestock's market price is lower than the compensation payment, the herder will always exert some effort in livestock protection. Performance payments are simply a lump sum payment per carnivore, irrespective of livestock protection and actual losses. They would cover the cost of livestock losses in case of zero protection and thus are more expensive than ex-post compensation payments which are only issued for actual losses.

Linearity of $k^{i}(W(l))$ means that a marginal carnivore will prey on a constant number of livestock. A convex shape describes positive scale effects in the carnivores' hunting techniques. This may be relevant for carnivore species that are more efficient predators when they hunt in packs, e.g. wolves. Concavity may occur for carnivore species which, with increasing population densities, face intraspecies crowding-out effects. For example, carnivores spend substantial amounts of time and energy on defending their territories and thus prey on relatively less livestock.

Comparing the cost of an ex-post compensation payment scheme in case of a non-separable predation function (LHS of 17) to the cost of a performance payment scheme (RHS of 17) we find that which scheme is less expensive is ambiguous 


$$
Z_{W} \Omega \stackrel{\leq}{\geq} Z_{W}
$$

with $\Omega=\frac{k\left(W\left(l^{S P}\right), a^{L H}\right)}{k_{W}^{L H} W\left(l^{S P}\right)}+\frac{p\left(k_{W}^{L H}-k_{W}^{S P}\right) k\left(W\left(l^{S P}\right), a^{L H}\right)}{Z_{W} k_{W}^{L H} W\left(l^{S P}\right)}$

Both schemes are equally expensive if $\Omega=1$.

The question is then how the cost of the two schemes develops if protection effort deviates from the level that leads to equality of the two schemes. Since $\Omega_{a} L H<0$ (for $r>0$ ) a decrease in the herder's protection effort below the level for which $\Omega=1$ will lead to an inequality in (17) indicating that ex-post compensation is more expensive than a performance payment scheme. Should the herder's protection effort level increase beyond this level, expost compensation would in turn become less expensive than a performance payment scheme.

\section{Empirical Analysis}

As discussed before, wildlife-livestock conflicts are most severe in a developing country context. Tigers (Panthera tigris) are one of the carnivore species that are currently facing dramatic declines in population size. India's tiger population is estimated at only approximately 1,400 individuals (Jhala et al. 2008). Currently there are two different conservation policy approaches implemented in India. Convicted poachers face fines and prison sentences. Next to punishments for poaching, compensation payment schemes are installed in the buffer zones of many tiger reserves. Recently, however, park managers, conservationists, and policy makers expressed general interest in the conservation performance payments approach (Damania et al. 2008).

The data we use for the analysis is collected from various case studies and conservation reports. They are very rough estimates and although they are drawn from the available literature, we do not claim they necessarily are good representations of the actual ecological and economic relationships. Most prominently, there still is a research gap concerning the function for tigers' existence value. We thus show results for a range of marginal existence values that result in an interior solution of the model.

In this empirical analysis, tigers' livestock predation technology is described by a separable function. The goal of the empirical analysis below is to provide an indication of how the model could be used for policy implications if reliable data were available. The functional forms and data sources used here are listed in Table 1.

For the given data, the model arrives at an interior solution as long as the marginal existence value is below INR4888. Figure 1 depicts the social planner's optimal tiger population for a park with a carrying capacity of 216 tigers dependent on the prevailing marginal existence value. Prior to the implementation of any policies, the livestock herder's optimal carnivore population is 60 tigers.

The question now is which policy mechanism should be implemented to provide the livestock herder with incentives to increase the carnivore population up to the social planner's optimum. As discussed in the theoretical section above, both ex-post compensation and performance payments can provide pro-conservation incentives. For the given data, Fig. 2 shows the costs for a performance payment resp. ex-post compensation scheme dependent on the policy goal in terms of tiger numbers. The horizontal axis indicates the hypothetical policy goals and the vertical axis shows the corresponding cost for both scheme types. For the given data, ex-post compensation is less expensive than performance payments. If there is no deviation between the social planner's and the livestock herder's optimal tiger population, obviously no payment is necessary. 
Table 1 Values and functional forms used in empirical analysis

\begin{tabular}{|c|c|c|c|}
\hline Variable & & Value or functional form & Data source \\
\hline $\bar{W}$ & Carrying capacity & 216 & $\begin{array}{l}\text { Damodaran (2007) } \\
\text { (for an average sized } \\
1,350 \text { sqkm reserve) }\end{array}$ \\
\hline$W(l)$ & Carnivore stock & $\frac{\bar{W}}{l^{0,5}}$ & $\begin{array}{l}\text { Damania et al. (2003) } \\
\text { (for computational } \\
\text { ease poaching } \\
\text { technology } l^{0.46} \\
\text { was rounded to } l^{0.5} \text { ) }\end{array}$ \\
\hline$k(W(l), a)$ & $\begin{array}{l}\text { Tigers' livestock } \\
\text { predation } \\
\text { technology }\end{array}$ & $5 * W(l)-\frac{\bar{W}}{a^{0.5}}$ & $\begin{array}{l}5 * W(l): \text { Tigers are } \\
\text { estimated to prey on } \\
\text { appr. the equivalent } \\
\text { of } 50 \text { wild ungulates } \\
\text { per year. Scat } \\
\text { analyses revealed } \\
\text { that } 10 \% \text { of tigers' } \\
\text { diet is livestock } \\
\text { (Bagchi et al. 2002). } \\
\text { Livestock protection } \\
\text { technology is } \\
\text { assumed to be the } \\
\text { non-lethal } \\
\text { equivalent to } \\
\text { poaching } \\
\text { technology }\end{array}$ \\
\hline$p$ & $\begin{array}{l}\text { Price of goat } \\
\text { (per animal) }\end{array}$ & INR 1000 & Madhusudan (2003) \\
\hline$r$ & Off-farm wage rate & $\begin{array}{l}\text { INR }^{a} 12000 \text { (Proxy } \\
\text { for a year's salary } \\
\text { with INR } 40 \text { per } \\
\text { day.) }\end{array}$ & Damania et al. (2003) \\
\hline
\end{tabular}

${ }^{\mathrm{a}}$ INR $100 \approx$ USD $2.18($ March 2010$)$

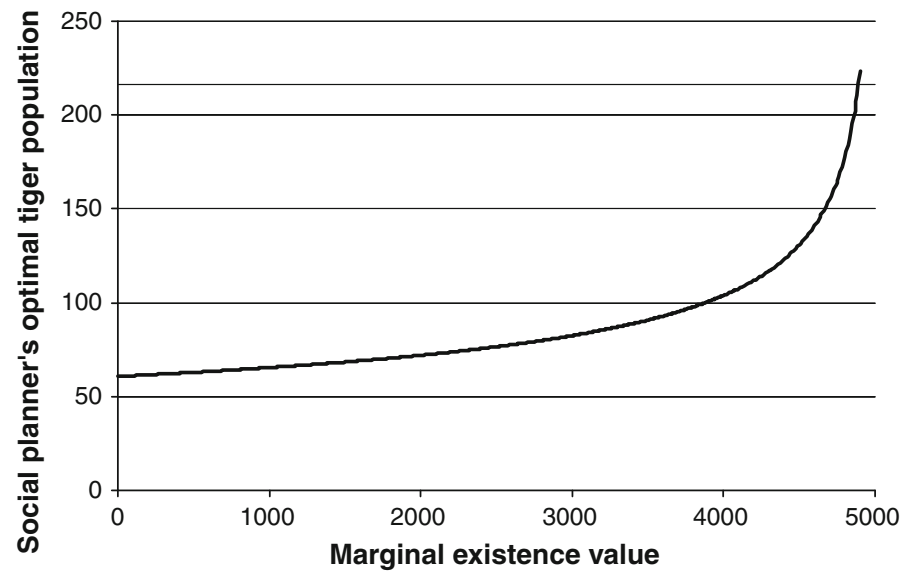

Fig. 1 The social planner's optimal tiger population for a range of marginal existence values. The assumed carrying capacity for the site in question is 216 tigers 


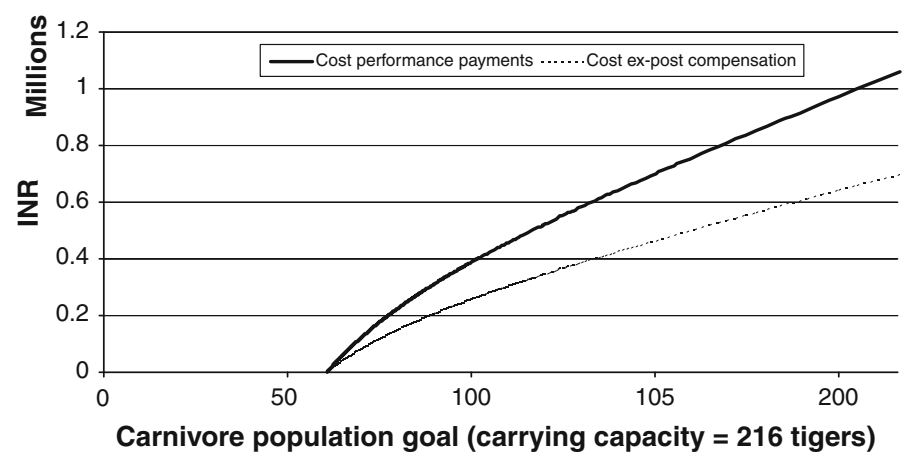

Fig. 2 Scheme costs dependent on the policy's tiger population goal

\section{Discussion}

In the previous sections we developed a model for a social planner and a livestock herder and compared the optimal carnivore populations that resulted from the models. As intuition suggested, the optimal carnivore population in the social planner model was higher than in the livestock herder model. We then analyzed the potential of the ex-post compensation policy to provide incentives for the livestock herder to reach the socially optimal carnivore population. Additionally, we analyzed a rather new policy approach, conservation performance payments, which in the carnivore conservation context is currently only implemented at a large scale in Sweden.

A result derived from the theoretical models is that both performance payments and expost compensation provide pro-conservation incentives. Ex-post compensation payments that are issued without any conditions on livestock protection measures were found to distort incentives to optimally protect livestock. In practice, this problem has been observed in some industrial countries (Swenson and Andren 2005), but may be of less concern in developing countries where compensation payments tend to be far below the actual value of the livestock, the process of filing for compensation is often cumbersome, and dependence of individual households on single animals is often high. Performance payments do not distort incentives to optimally protect livestock since the payments are directly linked to the conservation goal (e.g. the carnivore stock or carnivore offspring).

In section five, the model was analyzed with empirical data drawn from other models and case studies on tiger-livestock conflicts in India. Due to the existing knowledge gaps on tiger ecology and tigers' existence value, many functions in the empirical model are rather rough estimates. In particular there is a knowledge gap on tigers' existence value. Results were thus depicted for a range of possible marginal existence values that would lead to interior solutions of the model.

Which single scheme or mix of policies is optimal for a certain carnivore-livestock conflict will also always greatly depend on the specific context. An important factor that may influence the decision is the size of the budget available to set up, run, and monitor a scheme. Interestingly, our results indicate that the relative cost of an ex-post compensation scheme with a separable predation function versus a performance payment scheme depends on the functional response in the predator prey relationship. The discussion of the alternative policies focused on assessing the amount of payments that are necessary to achieve certain 
policy goals. However, the models could also be utilized to compute which level of carnivore conservation is theoretically realizable with a given budget.

Apart from budget issues, the degree of effective law enforcement in a country is also of importance. Livestock herders will want to have securities of being able to claim the payments they are entitled to. Corruption can be a great obstacle for all types of schemes. Corruption together with a lack of public confidence in wildlife management authorities provide dim prospects for the success of any scheme, no matter how well designed it is (Ferraro 2005). Another obstacle in developing countries is that any type of payment scheme might act as a welfare magnet, attracting people to move to the carnivore dense areas.

Next to the more general framework conditions, understanding how livestock herders make decisions is crucial when designing incentive-based schemes. Profound knowledge of socio-economic household factors may prove to be essential. For example, people in some rural regions of India are strictly vegetarian whereas in others they are not. Incentives that, e.g. aim at reducing competition between livestock and carnivores' natural prey species by increasing livestock harvest rates may simply not work in regions where there is no market for meat. Similarly, infrastructure availability may determine whether off-farm work is a real alternative to agriculture. Many more such examples could be mentioned, but which socio-economic factors are most relevant will always vary from case to case.

There are several lines of possible extension to the model presented here. An obvious one is the consideration of multiple livestock holders. Another one would be to investigate the dynamics of carnivore and livestock population developments under different policy schemes.

Acknowledgments We acknowledge funding from the Swiss North-South Centre and the Swedish Research Council for Environment, Agricultural Sciences and Spatial Planning, FORMAS.

\section{References}

Albers H, Ferraro PJ (2006) Economics of biodiversity conservation in developing countries. In: Toman M, Lopez R (eds) Economic development and environmental sustainability: new policy options. Oxford University Press, New York

Andrén H, Linnell JDC, Liberg O, Andersen R, Danell A, Karlsson J, Odden J, Moa PF, Ahlqvist P, Kvam T, Franzén R, Segerström P (2006) Survival rates and causes of mortality in Eurasian lynx (Lynx lynx) in multi-use landscapes. Biol Conserv 131:23-32

Bagchi S, Goyal S, Sankar K (2002) Prey abundance and prey selection by tigers (Panthera tigris) in a semiarid, dry deciduous forest in western India. J Zool 260:285-290

Bostedt G (2001) Reindeer husbandry, the Swedish market for reindeer meat, and the chernobyl effects. Agri Econ 5:213-222

Bostedt G (2005) Pastoralist economic behaviour: empirical results from reindeer herders in northern Sweden. J Agric Resour Econ 30:381-396

Butler JRA (2000) The economic costs of wildlife predation on livestock in Gokwe Communal Land, Zimbabwe. East Afr Wildl Soc 38:23-30

Bulte E, Rondeau D (2007) Compensation for wildlife damages: habitat conversion, species preservation and local welfare. J Environ Econ Manage 54:311-322

Casey F, Vickerman S, Hummon C, Taylor B (2006) Incentives for biodiversity conservation: an ecological and economic assessment. Defenders of Wildlife, Washington DC

Casey F, Boody G (2007) An assessment of performance-based indicators and payments for resource conservation on agricultural lands. Report for the multiple benefits of agriculture initiative. Conservation economics white paper 8, Defenders of wildlife, Washington DC

Damania R, Stringer R, Karanth U, Stith B (2003) The economics of protecting tiger populations: linking household behaviour to poaching and prey depletion. Land Econ 79:198-216

Damania R, Seidensticker J, Whitten T, Sethi G, Mackinnon K, Kiss A, Kushlin A (2008) A future for wild tigers. World Bank, Washington DC 
Damodaran A (2007) The project tiger crisis in India: moving away from the policy and economics of selectivity. Environ Values 16:61-77

Danell A, Andrén H, Segerström P, Franzén R (2006) Space use by Eurasian lynx in relation to reindeer migration. Can J Zool 84:546-555

Engel S, Pagiola S, Wunder S (2008) Designing payments for environmental services in theory and practice: an overview of the issues. Ecol Econ 65:663-674

Ferraro PJ, Simpson RD (2002) The cost-effectiveness of conservation payments. Land Econ 78:339-353

Ferraro PJ (2005) Corruption and conservation: the need for empirical analysis. A response to Smith \& Walpole. Oryx 39:3

Fischer C, Muchapondwa E, Sterner T (2005) Bioeconomic model of community incentives for wildlife management before and after CAMPFIRE. Discussion paper 05-06, Resources for the Future, Washington $\mathrm{DC}$

Fourli M (1999) Compensation for damage caused by bears and wolves in the European union: experiences from LIFE-Nature projects. European Commission, Brussels

Gusset M, Swarner MJ, Mponwane L, Keletile K, McNutt JW (2009) Human-wildlife conflict in northern Botswana: livestock predation by endangered African wild dog Lycaon pictus and other carnivores. Oryx 43:67-72

Hazzah L, Borgerhoff Mulder M, Frank L (2009) Lions and Warriors: social factors underlying declining African lion populations and the effect of incentive-based management in Kenya. Biol Conserv 142:24282437

Hilton-Taylor C, Pollock CM, Chanson JS, Butchart SHM, Oldfield TEE, Katariya V (2009) State of the world's species. In: Vié J-C, Hilton-Taylor C, Stuart SN (eds) Wildlife in a changing world: an analysis of the 2008 IUCN red list of threatened species. IUCN, Gland, Switzerland

Holmern T, Nyahongo J, Roskaft E (2006) Livestock loss caused by predators outside the Serengeti National Park, Tanzania. Biol conserv 135:518-526

Inskip C, Zimmermann A (2009) Human-felid conflict: a review of patterns and priorities worldwide. Oryx 43:18-34

Jhala YV, Gopal R, Qureshi Q (eds) (2008) Status of tigers, co-predators and prey in India. National Tiger Conservation Authority and Wildlife Institute of India, Dehradun

Johansson P-O, Löfgren K-G (1985) The economics of forestry and natural resources. Blackwell, Oxford

Karanth KU, Chellam R (2009) Carnivore conservation at the crossroads. Oryx 43:1-2

Madhusudan MD (2003) Living amidst large wildlife: livestock and crop depredation by large mammals in the interior villages of Bhadra Tiger Reserve, South India. Environ Manage 31:466-475

Mishra C (1997) Livestock depredation by large carnivores in the Indian trans-Himalaya: conflict perceptions and conservation prospects. Environ Conserv 24:338-343

Mustelid Specialist Group (1996) Gulo gulo. In: 2004 IUCN red list of threatened species. Available at www. iucnredlist.org. Cited 06 Mar 2008

Nyhus PJ, Osofsky S, Ferraro P, Madden F, Fischer H (2005) Bearing the costs of human-wildlife conflict: the challenges of compensation schemes. In: Woodrooffe R, Thirgood S, Rabinowitz A (eds) People and wildlife: conflict or coexistence? Cambridge University Press, Cambridge

Persson J (2005) Female wolverine (Gulo gulo) reproduction: reproductive costs and winter food availability. Can J Zool 83:1453-1459

Persson J (2007) Järvens status och ekologi i Sverige. Report for the Governmental commission on the large carnivores (Utredningen om de stora rovdjuren). Department of Ecology, Grimsö Wildlife Research Station, Grimsö

Saberval V, Gibbs J, Chellam R, Johnsingh A (1994) Lion-human conflict in the Gir Forest, India. Conserv Biol 8:501-507

Singh I, Squire L, Strauss J (1986) Agricultural household models: extensions, applications, and policy. Johns Hopkins University Press, Baltimore

Skonhoft A (1998) Resource utilization, property rights and welfare: wildlife and the local people. Ecol Econ 26:67-80

Songorwa AN (1999) Community-based wildlife management (CWM) in Tanzania: are the communities interested? World Dev 27:2061-2079

Spence M, Zeckhauser R (1971) Insurance information, and individual action. Am Econ Rev 61:380-387

Swedish Government Bill (2000) Sammanhållen rovdjurspolitik. Government Bill 2000/01:57, Stockholm

Swedish National Council for Crime Prevention (2007) Poaching for large predators - conflict in a lawless land?. English summary of Brå report No 2007:22, Brå, Stockholm

Swenson J, Andren H (2005) A tale of two countries: large carnivore depredation and compensation schemes in Sweden and Norway. In: Woodroffe R, Thirgood S, Rabinowitz A (eds) People and wildlife: conflict or coexistance? Cambridge University Press, Cambridge 
Thirgood S, Woodroffe R, Rabinowitz A (2005) The impact of human-wildlife conflict on human lives and livelihoods. In: Woodroffe R, Thirgood S, Rabinowitz A (eds) People and wildlife: conflict or coexistence?Cambridge University Press, Cambridge

Wätzold F, Drechsler M (2005) Spatially uniform versus spatially heterogeneous compensation payments for biodiversity-enhancing land-use measures. Environ Resour Econ 31:73-93

Western D, Waithaka J (2005) Policies for reducing human-wildlife conflict: a Kenya case study. In: Woodroffe R, Thirgood S, Rabinowitz A (eds) People and wildlife: conflict or coexistence? Cambridge University Press, Cambridge

Woodroffe R, Lindsey P, Romanach S, Stein A, Ranah S (2005) Livestock predation by endangered African wild dogs (Lycaon pictus) in Northern Kenya. Biol Conserv 124:225-234

Wünscher T, Engel S, Wunder S (2008) Spatial targeting of payments for environmental services: a tool for boosting conservation benefits. Ecol Econ 65:822-833

Wunder S, Engel S, Pagiola S (2008) Taking stock: lessons learnt for the design of payments for environmental services programs. Ecol Econ 65:834-852

Zabel A, Holm-Müller K (2008) Conservation performance payments for carnivore conservation in Sweden. Conserv Biol 22:247-251 